\title{
Analysis of Key Component in Progressive Collapse Process of Offshore Jacket Platforms
}

\author{
Hong Lin* \\ College of Pipeline and Civil Engineering \\ China University of Petroleum \\ QingDao, China \\ *Corresponding author
}

\author{
Lei Yang \\ College of Science \\ China University of Petroleum \\ QingDao, China
}

\begin{abstract}
Progressive collapse, which is disproportional to the extent of initial damage, often brings a serious damage, even final failure to the structure, so it has attracted widespread attentions over the engineering field. In the design of offshore jacket structures for resisting progressive collapse, it is very necessary to evaluate the effect of each component on the whole structure, so as to recognize the critical components. In this paper, we present two kinds of evaluating indexs for the key component, respectively from the stress and the overall deformation energy point of view. Further, we study two different pattern of jacket platform structures, $K$-type and $X$-type, and calculate the index of each component. By using the method of removing component, we analyze the existing law of key components for different jacket type, and if we can enhance them, it will be great help to avoid progressive collapse of the jacket platform.
\end{abstract}

Keywords-offshore platform; collapse; key component; evaluating index

\section{INTRODUCTION}

During the long-term service period, the offshore platform structures will be confronted with kinds of emergencies [1], such as component fracture, ship collision, heavy object dropping, fire and explosion in local area, which usually causes a component failure, and produce a series of failure response resulting in a final collapse of the overall platform structure. This collapse mode is called progressive collapse [2-5], which exposes the weakness of structure resisting initial local failure and shows large potential dangers and hazards.

In fact, after one or several components of frame structure being failure, the remaining structure will make an attempt to seek and finally achieve a new balance state through load redistribution process, so as to resist the possible progressive collapse. Nevertheless, when the structure could not achieve a new balance state after a component failure, the progressive collapse of the platform structure will take place. Therefore, the components that could resist the continuous failure and form stable force transferring path are regarded as key components [6]. Due to the asymmetry of structure and loads, the stress of each basic component is not equal and the failure effects are different. Therefore, for the structure design of resisting progressive collapse, it is crucial to calculate and analyze the key component.

At present, there are some theory and methods about the redundancy, ductility and vulnerability of structure, which could be used to identify key components. Blockley [7] and Agarwal [8] present vulnerability assessment theory, being able to identify the weak point of structure through analyzing the effects of various initial damages. Ye [9] present an index of component importance, according to the energy formula. Also, there are some other researchers presenting a series of assessment methods based on strength, sensitivity and robustness methods [10]. This paper present a more feasible and practical method, which defines the sensitivity index from the strength of component and the viewpoint of energy. Further, combing with the alternative load path (ALP) method [2, 3], we carry out the assessment for the key components and analyze the existing state of key components.

\section{SENSITIVITY INDEX OF THE KEY COMPONENT}

\section{A. Sensitivity Index Based on the Bearing Strength}

Through analyzing the structural-load-carrying capacity change before and after component $r_{j}$ failure, the influence of component $r_{j}$ can be calculate as follows. Define $S_{i j}$ as the sensitivity index component $r_{i}$ to $r_{j}$

$$
S_{i j}=\left(\gamma-\gamma^{\prime}\right) / \gamma
$$

where $\gamma$ is the inner-stress of component $r_{i}$ before component $r_{j}$ failure, and $\gamma^{\prime}$ is the inner-stress of component $r_{i}$ after component $r_{j}$ failure. Then, the importance index of component $r_{j}$ can be defined as follows [6]:

$$
a^{j}=\sum_{i=1, i \neq j}^{n}\left|S_{i j}\right| /(n-1)
$$

where $n$ is the number of components.

Due to the strong operability and practicability of bearingcapacity method, it has been the widely used in the engineering application. However, for the complex structure with a large number of components, this method causes the difficulty of computer programming and large amount of calculations.

\section{B. Analysis of Key Component Based on Energy Method}

For the structure design of resisting progressive collapse, we use the deformation energy of the whole structure, so as to identify the key components.

Let $\boldsymbol{K}_{0}$ be the stiffness matrix of structure, $V$ be the displacement vector, and $P$ be the nodal load vector, then 


$$
P=K_{0} V
$$

Also, the work done by load $P$ can be expressed as follows:

$$
W=\frac{1}{2} P^{T} V=\frac{1}{2} V^{T} K_{0} V
$$

The deformation energy of the whole structure is as follows:

$$
U=\frac{1}{2} P^{T} K_{0} V
$$

Therefore, for the whole structure with a constant work done by external force, the more important the component is, the more significant the deformation of structure will be. Denote the stiffness matrix of structure by $\left[K_{0}\right]_{n \times n}$, and denote the contribution of component $r_{i}$ to the whole structure by $\left[k_{i}\right]_{n \times n}$, then the stiffness matrix of structure after removing component $r_{i}$ can be expressed as

$$
\left[K_{i}\right]_{n \times n}=\left[K_{0}\right]_{n \times n}-\left[K_{i}\right]_{n \times n}
$$

and after removing component $r_{i}$, the deformation energy of the whole structure is

$$
U_{i}=\frac{1}{2} P^{T} K_{i}^{-1} P
$$

Then, the importance index of component $r_{j}$ based on the energy method can be defined as follows [11]:

$$
b=\frac{U_{i}-U}{U}=\frac{P^{T} K_{i}^{-1} P-P^{T} K_{0}^{-1} P}{P^{T} K_{i}^{-1} P}
$$

Obviously, the larger the index $b$ is, the more significant the effect of component $r_{j}$.

\section{Finite Element Model of Jacket Structure}

\section{A. Finite Element Model}

Here, X-type and K-type offshore jacket platforms are employed as case study, so as to analyze the key components in different type platform. Pile foundation of the platform is at the 19.5 meters under the water surface, and the pile legs and pile foundation are connected by placing of concrete, regarded as rigid constraints. The Superstructure of the platform is at 6.5 meters above the water surface. Only vertical load of the structure weight is regarded as dead load, and floating ice load is considered as accidental load, acting on the water surface nodes. The material parameters, loads and boundary condition is listed in Table I.

TABLE I. MATERIAL PARAMETERS, LOADS AND BOUNDARY CONDITIONS

\begin{tabular}{|c|c|}
\hline Parameters & Value \\
\hline material density & $7.846 \mathrm{~kg} / \mathrm{m}^{3}$ \\
elasticity modulus & $2.06^{*} 10^{11}$ \\
Poisson's ratio & 0.3 \\
yield strength & $235 \mathrm{Mpa}$ \\
dead load & $400 \mathrm{KN}$ (vertical) \\
accidental load & $405 \mathrm{KN}$ (Horizontal) \\
\hline
\end{tabular}

In this paper, the element pipe20 in Ansys is used to establish finite element model of jacket platforms, and the $\mathrm{K}$ type and X type models are as shown in Figure I and Figure II, respectively.

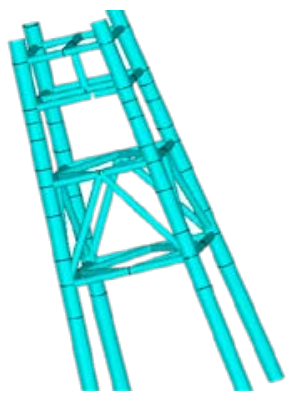

FIGURE I. K-TYPE PLATFORM MODEL

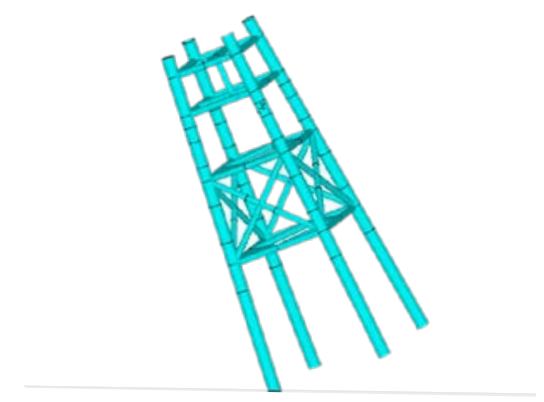

FIGURE II. X-TYPE PLATFORM MODEL

\section{B. Birth-Death Element Method of Ansys}

The birth-death element method is used to simulate removing component in Ansys. The stiffness matrix is modified in the birth-death element method [12], so as to realize stiffness mutation. Killing one element is not meaning to deleting the element in the finite element model, and just only to decreasing the stiffness of element. In general, killing one element is realized through multiplying an index coefficient $\left(1 * 10^{-6}\right)$ by the stiffness of element. When the element killed need to be activated again, the stiffness, mass and load parameters of the element just need to be set as the original value.

\section{NUMERICAL EXAMPLES}

Energy method is based on the stiffness matrix and only suitable for the elastic stage, so there exists some limitations in using the method to identify key components. Therefore, in the numerical examples, the bearing-capacity method is used to evaluate the sensitivity of component, and to identify the key components.

\section{A. Calculation of Key Component for X-type Jacket Platform}

For $j=1,2,3 \ldots$, the element $j$ is killed in turn, and the sensitivity index $S_{i j}$ can be calculated as Eq. (1). Further, for the element $j$, the importance index $a_{j}$ can be calculated as Eq. (2). Through calculations, the importance index of all elements are gained, and the largest 7 results are listed in Table II. 
TABLE II. THE LARGEST 7 IMPORTANCE INDEX

\begin{tabular}{|ccc|}
\hline $\begin{array}{c}\text { Element } \\
\text { No. }\end{array}$ & Importance index & Element Location \\
\hline 31 & 3.283 & Pile legs under water \\
17 & 3.255 & Pile legs under water \\
30 & 3.004 & Pile legs under water \\
15 & 2.976 & Pile legs under water \\
22 & 2.220 & Pile leg 1 at water surface \\
28 & 2.212 & Pile leg 4 at water surface \\
26 & 2.185 & Pile leg 3 at water surface \\
\hline
\end{tabular}

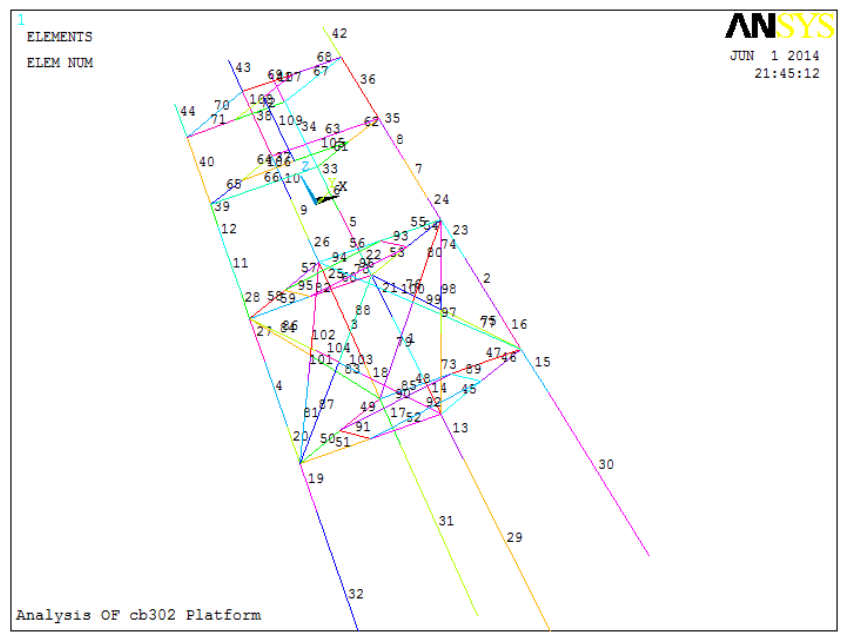

FIGURE III. ELEMENT NUMBER OF X-TYPE PLATFORM

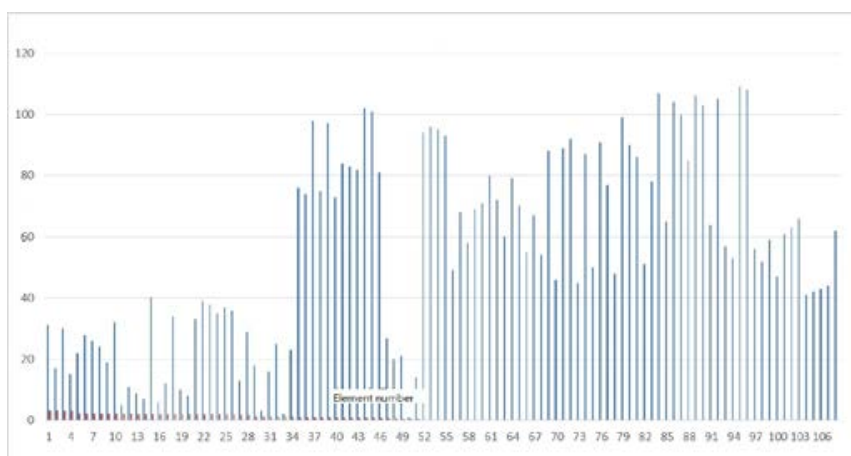

FIGURE IV. IMPORTANCE INDEX OF COMPONENTS OF X-TYPE PLATFORM

The results indicate that the largest 7 importance index all exist at pile legs under water or at the water surface. Also, the importance index of pile leg element is much larger than that of diagonal element. Therefore, we can conclude that the pile leg elements are the key components. Further, for the different elements in the pile legs, the importance index from large to small are as follows: Bottom elements in pile legs > Elements at water surface.

From the results, we have also found that the length of bottom element is much longer than the length of element at or above the water surface. Also, there is no diagonal elements at the 3 location, which indicates that the longer the element is, the larger the index of the element will be. That is to say, it can enhance the ability of structure resisting collapse through decreasing span and adding supporting components.

\section{B. Calculation of Key Component for K-type Jacket Platform}

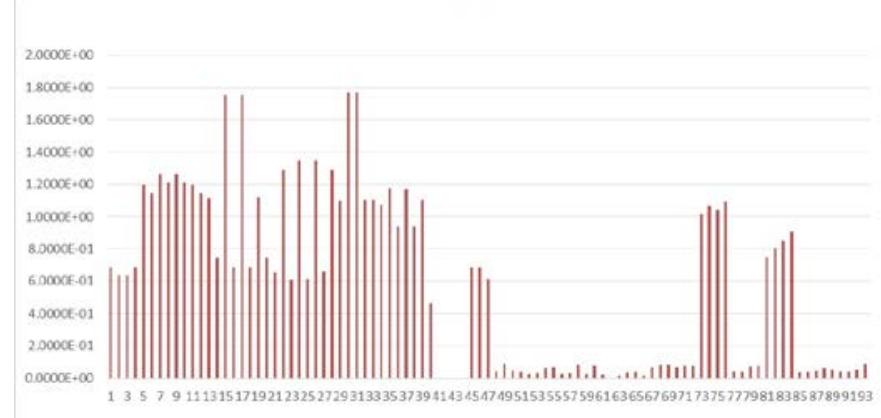

\section{FIGURE V. IMPORTANCE INDEX OF COMPONENTS OF K-TYPE} PLATFORM

Figure $\mathrm{V}$ shows that the importance index of each component in K-type jacket platform. The results indicate that the distribution rule of importance index of K-type platform is similar to the X-type platform.

\section{Comparisons of Key Components for the Two Type Jacket Platform}

From the analysis results of X-type and K-type platforms, we can conclude that the importance index is as follows: pile legs $>$ horizontal component $>$ diagonal component, and this is consistent with the actual situation.

Comparing the analysis results of X-type and K-type platforms, we have found that enhance the ability of structure resisting collapse through decreasing span and adding supporting components.

\section{ACKNOWLEDGMENT}

The work described in this paper was a part research work of Project (51209218) supported by National Natural Science Foundation of China, Project (14-2-4-58-jch) supported by Applied Basic Research Projects (Youth special) of Qingdao Science and Technology Program and Project (15CX05003A) supported by "the Fundamental Research Funds for the Central Universities” .

\section{REFERENCES}

[1] GERHARD E. Assessment of existing offshore structures for life extension[D]. University of Stavanger, NORWAY, 2005.

[2] General Service Administration. Progressive collapse analysis and design guidelines for new federal office buildings and major modernization projects[S] . 2003.

[3] Department of Defense 2010 (UFC4-023-03). Design of Structures to Resist Progressive Collapse[S]. 2010.

[4] Hu Xiaobin, Qian Jiaru. Overview of Analysis and Design Approaches for Progressive Collapse of Structures[J]. Building Structure, 2006, 36 (S1),pp. 79-83.

[5] MARJANISHVILI S M. Progressive analysis procedure for progressive collapse[J]. Journal of Performance of Constructed Facilities, 2004, 18(2), pp.79-85.

[6] CAI Jian-guo, WANG Feng-an, HAN Yun-long, et al.. Practical Method for the Evaluation of Important Structural Components of Long-span Space Structures. Journal of Hunan University (Natural Sciences), 2013,38(3), pp. 7-11. 
[7] Blockley D I, Agarwal J, Pinto T, et al . Structural vulnerability, reliability and risk[J]. Prog. Struct. Engng Mater, 2002, 4, pp. 203-212.

[8] Agarwal J, Blocldey D I, Woodman N J. Vulnerability of systems[J]. Civil Engineering and Environmental Systems, 2001, 18, pp. 141-165.

[9] YE Lieping, LIN Xuchuan, QU Zhe. Evaluating Method Element Importance of Structural System Based on Generalized Structural Stiffness [J]. Journal of Architecture and Civil Engineering, 2010, 27(1):1-6, 20

[10] GAO Yang, LIU Xila. Importance coefficients of components in evaluation of structure robustness. Chinese Journal of Rock Mechanics and Engineering,2008,27(12), pp. 2575-2584

[11] Zheng Yang. A study of critical element of the structure during the progressive collapse and sensitivity analysis[D]. Zhejiang University, 2013, pp. 47.

[12] GAO Yao-dong, HE Xue.Simulation of Welding Based on ANSYS Unit Birth and Death Technique. Heat Treatment Technology and Equipment, 2010, 31(1), pp. 51-54 